\title{
Ready to eat shelf-stable brown rice in pouches: effect of moisture content on product's quality and stability
}

\author{
Enrico Federici ${ }^{1,2} \cdot$ Valentina Gentilucci $^{1} \cdot$ Valentina Bernini $^{1}$ (1) $\cdot$ Elena Vittadini ${ }^{3}$ (I) $\cdot$ Nicoletta Pellegrini $^{4}$ (I)
}

Received: 23 February 2021 / Revised: 25 May 2021 / Accepted: 29 May 2021 / Published online: 15 September 2021

(c) The Author(s), under exclusive licence to Springer-Verlag GmbH Germany, part of Springer Nature 2021

\begin{abstract}
Despite several nutritional benefits of brown rice (BR) its consumption remains limited compared to white rice. Two of the major barriers to its consumption are long cooking time and limited shelf life. However, those two hurdles can be overcome through the development of shelf-stable BR pouches to create new ready-to-eat (RTE) products, a food category that is gaining important market shares. Nevertheless, scarce information is available on the production and shelf-life stability of ready-to-eat BR products. The first objective of this study was the determination of the optimal moisture range to fully cook BR. The second objective was to determine the effect of moisture content and storage time on two fundamental parameters for consumer's acceptance of rice: color and texture. Three RTE BR pouches with moisture contents of 54\%, 57\% and $60 \%$ were produced and texture and color were evaluated after 1 year of storage. Significant changes in hardness and stickiness were reported during long-term storage. Moisture content negatively affected hardness and positively affected stickiness. Furthermore, storage time and moisture showed a significant effect on rice color. The present results provide information that will be useful to design new RTE meals to promote brown rice consumption.
\end{abstract}

Keywords Brown rice $\cdot$ Ready to eat $\cdot$ Shelf life $\cdot$ Rice texture

\section{Introduction}

Ready-to-eat (RTE) meals are becoming popular among consumers due to their convenience and the change of eating habits. The busy lifestyles of young professionals and entrepreneurs have accounted for an increase in the demand for labor-saving RTE meals [1]. Availability of RTE meals has further gained importance in light of the COVID-19 pandemic, as they provide not only an easy solution to the need to minimize handling and contact-free delivery of food but

Elena Vittadini

elena.vittadini@unicam.it

1 Food and Drug Department, University of Parma, Parco Area Delle Scienze, 49/A, 43124 Parma, Italy

2 Department of Food Science, Purdue University, West Lafayette, IN 47907, USA

3 School of Biosciences and Veterinary Medicine, University of Camerino, via Gentile III da Varano 3, 62032 Camerino, MC, Italy

4 Department of Agricultural, Food, Environmental and Animal Sciences, University of Udine, via Sondrio 2/A, 33100 Udine, Italy also are a lunch option alternative for individuals who would have normally fed at restaurants that have been largely shut down [2-4].

Rice is a popular ingredient in RTE food in Europe, America and Asia [5], and it is commonly consumed and used in RTE as polished (white) rice. White rice is preferred from consumers to brown rice (BR) since the latter has a longer cooking time, chewy texture, and poor appearance [6-8]. Moreover, products incorporating BR also negatively impact the flavor of a product [9]. However, BR has positive nutritional features as it is rich in dietary fiber, polyphenols, and lipids which are available in good amounts in the bran layer of caryopsis [10]. Compared to BR, white rice has a poorer nutritional value as, during milling, removal of bran and germ diminishes fiber, vitamins and minerals as well as protein content [11]. Thus, the utilization of BR in RTE foods could be a good strategy to increase not only its nutritional value but also take out the burden of long cooking time [12].

A popular technology to produce RTE cereal products is sterilization in pouches. However, when this intense thermal treatment is performed on white rice grain, its integrity is lost resulting in a sticky product with a soft texture. A 
potential solution to produce rice-based RTE aseptic products is the utilization of BR. The long cooking time of BR is a positive feature for aseptic processing since it allows to sterilize the product with limited effects on grain structural integrity. Aseptic processing also removes the need for long cooking by the consumer, which is a barrier for BR consumption. Furthermore, the use of BR, instead of white rice, as the main ingredient in these highly processed foods, which are potentially associated with poor dietary quality and obesity [13], could greatly improve their nutritional value. Fiber, minerals and proteins present in BR are not lost during the cooking-sterilization process in an enclosed pouch, and bioactive compounds present in rice bran are more available after being thermally treated [14]. Finally, $\mathrm{BR}$ rice contains a higher amount of bioactive lipids and flavonoids than white rice [15] which may further support the human immune system also against COVID-19 [16]. All these characteristics make BR an optimal candidate for the design of RTE BR-based functional foods. Such RTE products could be a mean to contribute significantly to increase the consumption of BR and to help consumers in familiarizing with the consumption of whole-meal foods [6].

To the authors' best knowledge, no information is available in the literature on the optimization of RTE BR cooking process in pouches, and on the characterization of its shelflife stability. In this study, cooking conditions of BR have been optimized at first, and then, the effect of hydration level and storage time on main quality attributes (e.g. texture and color) of RTE BR have been evaluated.

\section{Materials and methods}

\section{Brown rice optimal cooking time determination}

BR of Roma variety has been gently provided by a local producer (Grandi Riso S.p.A., Codigoro, Ferrara, Italy). Rice was cooked in boiling water (1:20, rice:water) in a pot for variable lengths of time $(10,15,20,25,30,35,40$ and $45 \mathrm{~min}$ ). BR and cooking water were separated by draining rice with a colander and cooled down to room temperature for $30 \mathrm{~min}$ before further analysis. The minimum cooking time to consider BR cooked was calculated through the determination of the point of inflection of the rice moisture absorption curve [17]. All the experiments were carried out at the Department of Food and Drug, University of Parma (Italy).

\section{Brown rice moisture content}

The moisture content of $\mathrm{BR}$ at variable cooking times was evaluated by drying in an air forced oven at $105{ }^{\circ} \mathrm{C}$ to constant weight according to AACCI method 44-15.02. The analysis was performed in triplicate for each cooking time.

\section{Brown rice texture}

Texture profile analysis (TPA) was performed on rice samples using a Texture Analyzer (Stable Micro Systems, Godalming, UK) equipped with a $25 \mathrm{~kg}$ load cell and an aluminum cylinder probe with a diameter of $40 \mathrm{~mm}$, following Boluda-Aguilar et al. [2] with some modification. A test speed of $0.1 \mathrm{~mm} / \mathrm{sec}$ and a total strain of $75 \%$ were used. Three $g$ of rice was spread in single layer grain on the instrument base. Three replicates were performed on each sample. Textural attributes considered were: hardness $(\mathrm{N}$, maximum force of the first compression) and stickiness $\left(\mathrm{N} . \mathrm{cm}^{-1}\right.$, negative area after the first compression) [18].

\section{Brown rice grain morphology}

Forty BR kernels were arranged in a thin layer on a transparent plastic sheet. A dimensional reference was added to determine pixel:mm ratio of every image. BR pictures were acquired using a scanner (HP Scanjet 8200) with a resolution of 600 pixel and analyzed with the software ImageJ [19]. Acquired images were then converted in black and white and threshold adjusted before measuring the averaged area, solidity, and circularity of rice kernels.

\section{Brown rice cooking loss}

Cooking loss, defined as the amount of solids lost into the cooking water, was determined according to the AACC official method 16-50.

\section{RTE brown rice poches production and microbial safety assessment}

RTE BR pouches were produced by a local producer. BR was washed, inserted into a pouch ( $250 \mathrm{~g}$, composite packaging, 406,735, Goglio Packaging System, Milan, Italy) together with enough tap water to reach theoretical total moisture contents of 54, 57, and $60 \mathrm{~g}$ water $/ 100 \mathrm{~g}$ product. Pouches were then hermetically sealed, placed vertically into baskets that were then inserted into a horizontal autoclave, which was first filled with water at $85^{\circ} \mathrm{C}$, heated to $118^{\circ} \mathrm{C}$ and held for $35 \mathrm{~min}$. The cooking-sterilization process was static, not allowing for pouches rotation. At the end of the thermal treatment, pouches were cooled down, unloaded, and stored at room temperature to reproduce domestic preservation conditions. One pouch was open for every point of shelf life at the following times: 0, 40, 80, 120, 160, 270, and 365 days. For every storage time, microbiological analysis was performed to assess the sterility of the product. Aliquot 
of samples were homogenized 1:10 (Seward Stomacher, 400 circulator, UK) with sterile Ringer solution (Oxoid, Basingstoke, UK), tenfold diluted and plated in duplicate on different culture media. Total mesophilic and spore-forming mesophilic bacteria were determined on Plate Count Agar (PCA) (Oxoid, Basingstoke, UK) after incubation at $30{ }^{\circ} \mathrm{C}$ for $48 \mathrm{~h}$. Yeast and molds were grown on Yeast Extract Dextrose Chloramphenicol Agar (YEDC) (REMEL Lenexa, USA) after incubation at $25^{\circ} \mathrm{C}$ for $72-120 \mathrm{~h}$. Brilliance ${ }^{\mathrm{TM}}$ Bacillus cereus Agar Base supplemented with Brilliance ${ }^{\mathrm{TM}}$ Bacillus cereus selective supplement (Oxoid, Basingstoke, UK) and incubated at $37{ }^{\circ} \mathrm{C}$ for $48 \mathrm{~h}$ was used to enumerate Bacillus cereus. Regarding spore-forming bacteria, first dilution of the samples was treated at $85^{\circ} \mathrm{C}$ for $15 \mathrm{~min}$ before plate counts. Analyses were carried out in duplicate and for each sampling time average values \pm standard deviations were reported as UFC/g.

\section{Water spatial distribution in pouches}

Brown rice moisture content homogeneity throughout the pouch was assessed by means of its moisture content, by extracting rice samples from 24 different locations in the pouch. Sampling locations were equally distanced to assure homogeneous distribution of sampling points through the pouch. Moisture content was then determined as described in 2.1.1. Moisture spatial distribution was measured in three pouches per each BR moisture content.

\section{Brown rice color in pouches}

Color was measured on the surface of cooked BR using a Minolta Colorimeter (CM 2600d, Minolta Co., Osaka Japan) in the 400-700 $\mathrm{nm}$ range using illuminant D65 and for a $2^{\circ}$ position of the standard observer. $\mathrm{L}^{*}$ (lightness), $\mathrm{a} *$ (redness), $b *$ (yellowness) were measured for at least ten measurements at each cooking time and each shelf-life time. $\Delta \mathrm{E}$ was calculated according to Eq. 1, taking the color of rice cooked at time 0 as reference.

$\Delta E=\sqrt{(L 1-L 2)^{2}+(a 1-a 2)^{2}+(b 1-b 2)^{2}}$

\section{Brown rice texture in pouches}

Each BR pouch was massaged to un-grain and mix their content prior to be opened to extract BR samples $(80 \mathrm{~g})$. Samples were transferred into a closed container and heated in a microwave for $1 \mathrm{~min}$ at $900 \mathrm{~W}$, to replicate a standard heating procedure the product would undergo prior to consumption. Heated rice was allowed to cool down to room temperature prior to texture profile analysis (TPA) that was performed as described in "Brown rice texture".

\section{Statistical analysis}

Data are presented as average \pm standard deviation. At least three replicates were performed for each analysis. Significant differences $(p \leq 0.05)$ among samples were calculated by multivariate analysis of variance (MANOVA) with a Tukey-high significant difference test. SAS 9.4 (SAS institute corporation, NC, USA) was used to perform the statistical analysis.

\section{Results and discussion}

\section{Brown rice optimal cooking time determination}

The cooking process of BR in excess water was studied with respect to water uptake and textural changes occurring in rice kernels for different lengths of time. This preliminary study was carried out to determine the amount of water needed to reach optimal cooking of BR, and therefore to design conditions to achieve optimal cooking of BR within sealed pouches. Optimal cooking time has been reported to correspond with the point at which most of the starch present in the kernel is gelatinized, condition that can be determined with the inflection point of a moisture absorption kinetic curve [17]

Appearance of BR after cooking for different times is shown in Fig. 1. BR kernels cooked up to 20 min were characterized by a smooth surface and retained their original shape and structural integrity. At 25 min cooking, BR kernels started to break due to moisture absorption and volume expansion indicative of an important amount of gelatinized starch. The number of broken kernels increased with cooking time and their shape become progressively more irregular. After $45 \mathrm{~min}$, an important amount of starch leached out from the kernels, as it was observable by the presence of a large quantity of material collecting on the plastic sheet used to arrange the sample for image acquisition. BR kernels area was measured as a function of cooking time (Table 1), and it was found to progressively increase from $20.9 \pm 2.7$ to $25.3 \pm 3.7 \mathrm{~mm}^{2}$ with cooking time increase from 10 to 25 min. Rice kernels expansion is due, primarily, to water absorption, the consequent swelling, and gelatinization of starch granules during cooking. However, after $25 \mathrm{~min}$ of cooking, even though rice kept absorbing water, its area increased at a slower pace, suggesting that rice starch had reached its maximum swelling ability and was not able to further expand [20]. At longer cooking times, BR kernels underwent breakage and disruption decreased their solidity, circularity and slightly, but nor significantly, increased their overall area (Table 1).

Water uptake in BR during cooking was monitored and it was found, as expected, to increase with increasing cooking 
Fig. 1 Appearance of brown rice kernels after cooking in a pot for different lengths of time
Table 1 Area, solidity and circularity of brown rice kernels cooked in a pot at different cooking times
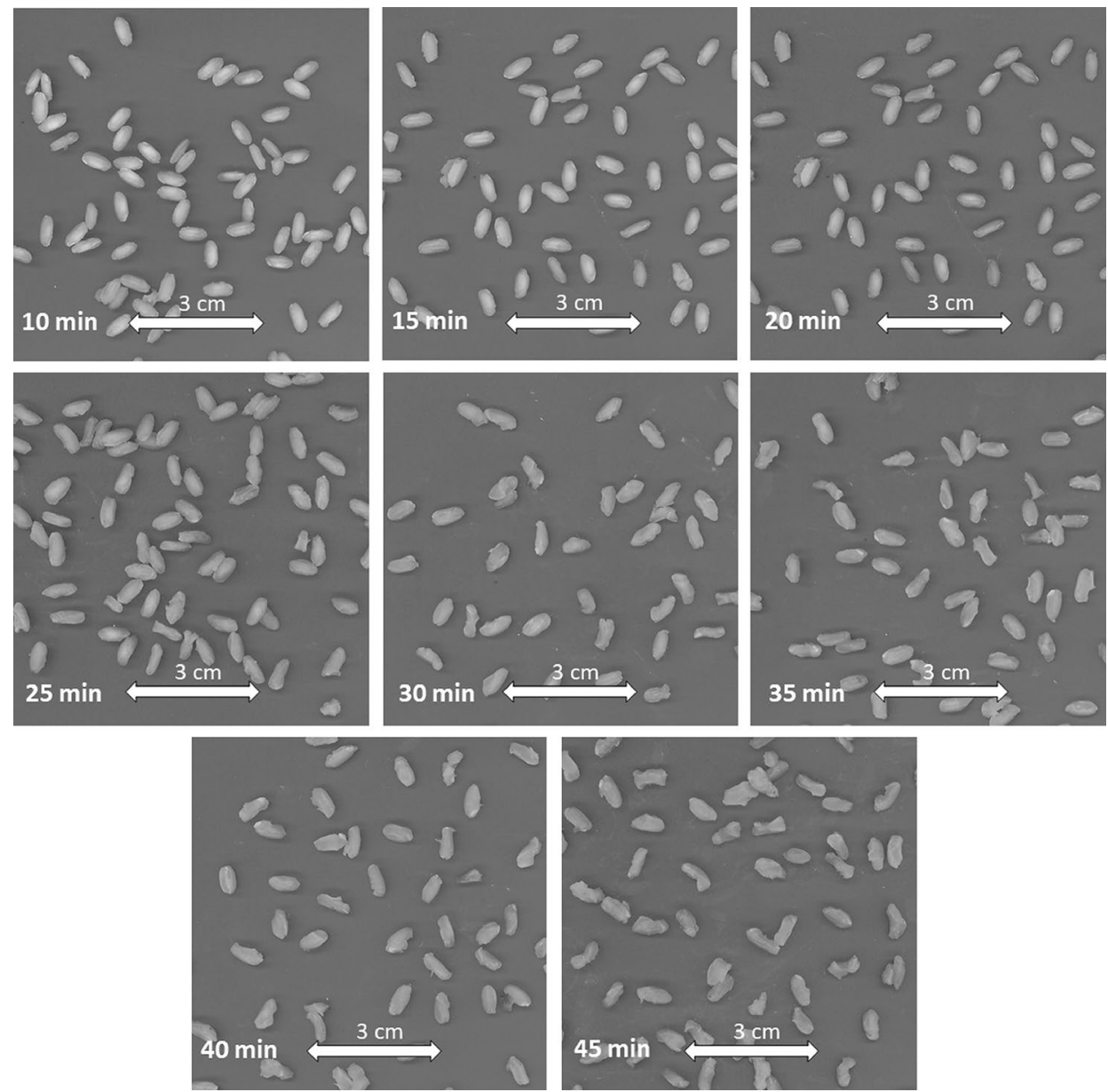

\begin{tabular}{lllllllll}
\hline & $10 \min$ & $15 \min$ & $20 \min$ & $25 \min$ & $30 \min$ & $35 \min$ & $40 \min$ & $45 \min$ \\
\hline Area & $20.9^{\mathrm{c}}$ & $22.9^{\mathrm{b}, \mathrm{c}}$ & $24.6^{\mathrm{a}, \mathrm{b}, \mathrm{c}}$ & $25.3^{\mathrm{a}, \mathrm{b}, \mathrm{c}}$ & $25.2^{\mathrm{a}, \mathrm{b}}$ & $25.8^{\mathrm{a}, \mathrm{b}}$ & $26.0^{\mathrm{a}}$ & $26.2^{\mathrm{a}}$ \\
Solidity & $0.672^{\mathrm{a}}$ & $0.677^{\mathrm{a}}$ & $0.707^{\mathrm{a}}$ & $0.648^{\mathrm{b}}$ & $0.639^{\mathrm{b}}$ & $0.62^{\mathrm{b}, \mathrm{c}}$ & $0.62^{\mathrm{b}, \mathrm{c}}$ & $0.603^{\mathrm{c}}$ \\
Circularity & $0.936^{\mathrm{a}}$ & $0.94^{\mathrm{a}}$ & $0.944^{\mathrm{a}}$ & $0.926^{\mathrm{a}, \mathrm{b}}$ & $0.909^{\mathrm{b}}$ & $0.91^{\mathrm{b}}$ & $0.905^{\mathrm{b}}$ & $0.89^{\mathrm{b}}$ \\
\hline
\end{tabular}

Letters indicate significant differences among samples on the same row $\mathrm{p}<0.05$

time (Fig. 2). Moisture content of BR gradually increased from $38.0 \pm 0.2$ to $52.9 \pm 0.8 \mathrm{~g}$ water $/ 100 \mathrm{~g}$ product up to 25 min cooking. At longer cooking times, water absorption still occurred but at a slower rate, reaching a maximum of $64.9 \pm 0.2 \mathrm{~g}$ water $/ 100 \mathrm{~g}$ product at $45 \mathrm{~min}$ cooking. From the data reported in Fig. 2, it is possible to observe the occurrence of an inflection after 25 min of cooking, leading to the identification of $25 \mathrm{~min}$ as the minimum cooking time at which the rice could be considered cooked in excess boiling water [17]. Solid loss from BR kernels increased exponentially with increasing cooking time, as measured by the increase in turbidity of the cooking water (Fig. 2), resulting from solids (primarily amylose and short-chain amylopectin) lost in cooking water [21]. At the initial stages of cooking, turbidity grew slowly due to the limited starch gelatinization with few broken starch granules and the presence of intact husks that protected and retained the starchy endosperm within the kernel. Increasing cooking times lead to more extensive gelatinization and an increasing number of kernels showing damaged husks, resulting in an increased release of solids.

Textural attributes of BR significantly changed upon cooking due to water absorption and structural changes occurring in rice constituents, primarily associated with starch gelatinization. BR hardness was very high at the beginning of the cooking process, $255.1 \pm 11.6 \mathrm{~N}$ after $10 \mathrm{~min}$ of cooking, and gradually decreased, as expected, to $56.4 \pm 6.8 \mathrm{~N}$ after $45 \mathrm{~min}$ of cooking. Hardness decrease 
Fig. 2 Changes in physicochemical attributes of brown rice (moisture content, kernel area, hardness) and cooking water (turbidity) during cooking. Gray area represents the range of acceptable cooking conditions

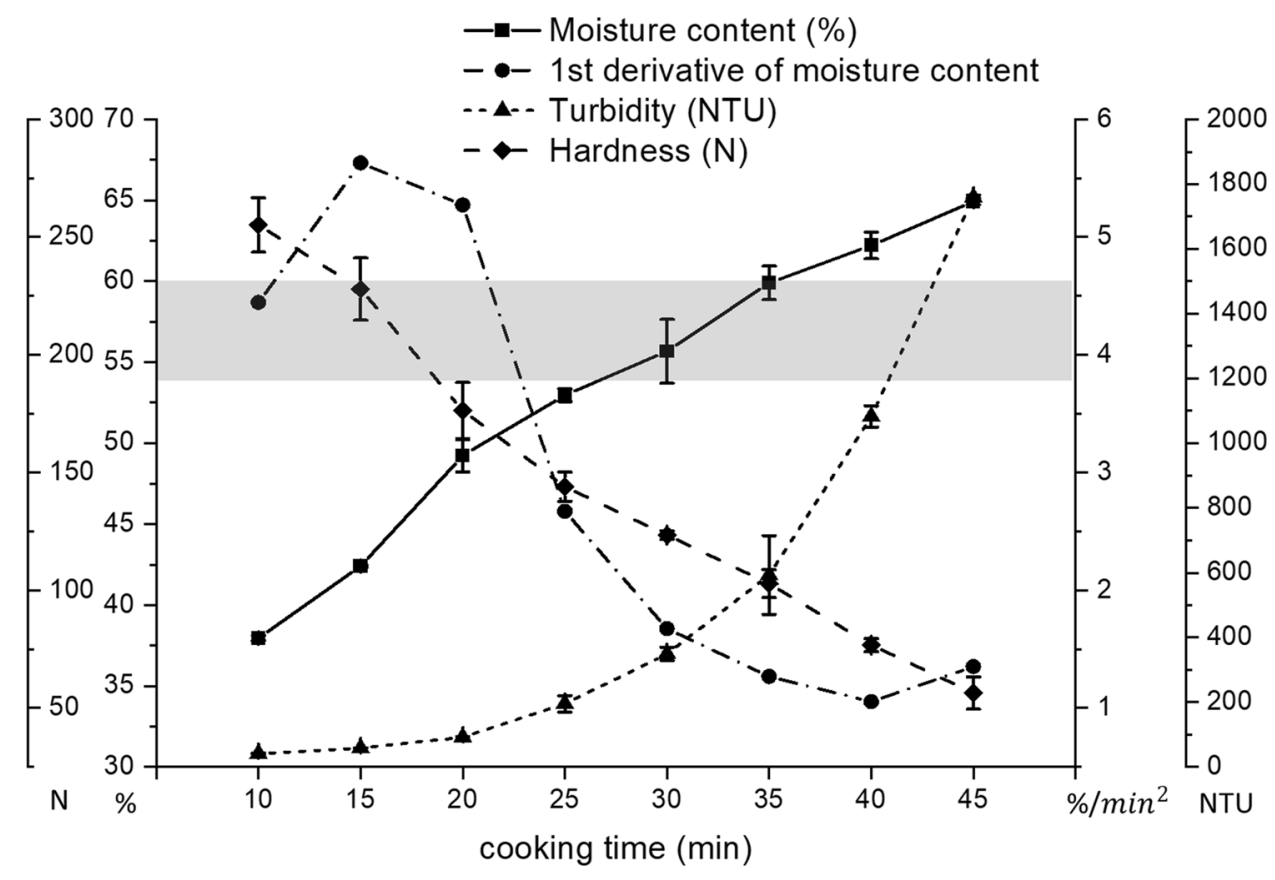

could be divided into two phases reflecting the trend observed for moisture uptake. A first phase, characterized by a rapid decrease in hardness, was observed until $25 \mathrm{~min}$ of cooking, and a slower decrease for further cooking from 25 to $45 \mathrm{~min}$.

Studies on the degree of starch gelatinization at variable cooking times in pasta [22] indicated that only $80 \%$ of starch was gelatinized at the cooking time suggested by the pasta producer, while $90 \%$ starch gelatinization was reached only in an overcooked product. In this respect, a complete starch gelatinization is not required to consider a product cooked [23]. Therefore, we can expect starch to be mainly gelatinized in BR at the inflection point where water uptake is reduced, but it can be considered cooked over a larger range of moisture contents.

In this work, the extremes of BR cooking were set, for the lower limit, in correspondence of the inflection point of the moisture uptake curve ( $25 \mathrm{~min}$, corresponding to a reduction of water uptake), and for the higher limit, at $35 \mathrm{~min}$. The value of $35 \mathrm{~min}$ was selected because it corresponded to a condition where kernel damage was still contained. This statement was supported by limited turbidity of the cooking water (593 NTU) and BR kernel high stickiness $\left(8.4 \pm 2.1 \mathrm{~N} \mathrm{~cm}^{-1}\right)$ as compared to $1082 \mathrm{NTU}$ and $4.2 \pm 0.8 \mathrm{~N} \mathrm{~cm}^{-1}$, respectively, at 40 min cooking, indicating a shift of solids from BR kernel surface into the cooking water. The moisture content of rice at the lower (25 $\mathrm{min}$ ) and higher (35 $\mathrm{min}$ ) end of the cooking range were $52.9 \% \pm 0.8$ and $59.9 \% \pm 1.0$, respectively. Based on the results obtained, the moisture contents to cook rice in pouches were designed to be 54,57 and $60 \%$.

\section{RTE brown rice in pouches: characterization and long-term shelf-life stability}

\section{Moisture content and spatial distribution in pouches}

Rice was cooked in pouches with the theoretical amount of water to reach the minimal amount of moisture necessary to cook the rice. Total mesophilic bacteria, spore-forming bacteria, yeasts and molds and B. cereus were not present above the detection limit (10 UFC/g) throughout the shelf life considered, confirming the efficacy of the treatment. At the end of aseptic processing, which was carried out in a static manner, the real moisture content of rice was determined. The average moisture content of BR in the pouches was $53.9 \% \pm 3.8,57.1 \% \pm 0.7$ and $60.3 \% \pm 0.5$ and well approximated the theoretical target moisture contents (54\%, $57 \%$, and $60 \%$ moisture content, respectively). The averaged moisture content of all samples remained constant for the duration of the storage time (1 year).

Water content in different locations of the pouches was measured to verify homogeneity of the cooking process inside pouches to ensure the product's uniformity. Water distribution was not homogenous in the $54 \%$ moisture pouch, while it was evenly distributed throughout the sample in other pouches (57 and 60\%), as shown in Fig. 3. BR in the $54 \%$ moisture pouch had a higher moisture content 


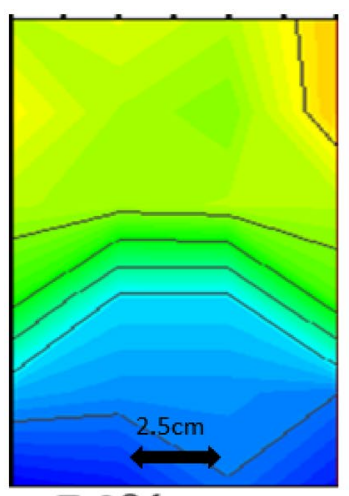

$54 \%$ water

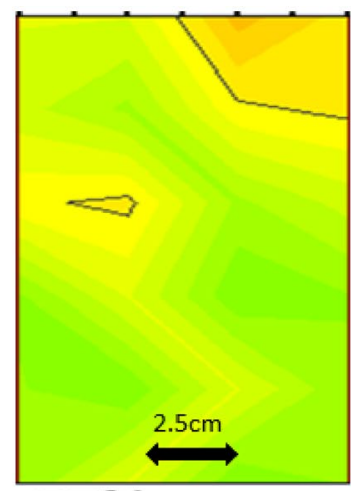

$57 \%$ water

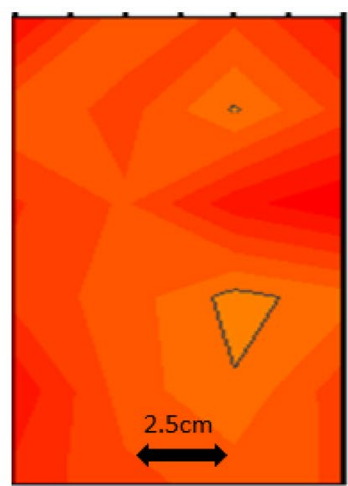

$60 \%$ water

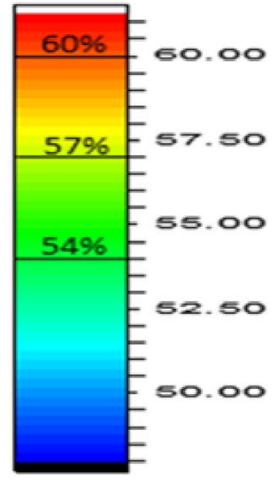

Fig. 3 Moisture content of brown rice as a function of spatial distribution in pouches with different theoretical moisture contents at the top and a lower at the bottom of the pouch (Fig. 3). This can be explained by the dynamics of the cooking process in a confined environment (pouch); upon heating, water turns into vapor and moves towards the upper zone of the pouch, creating a dis-uniform distribution of water that is particularly relevant in the lower moisture product. An uneven water distribution causes a different degree of water penetration into rice kernel and, consequently, uneven cooking of the product. Water availability affects starch gelatinization temperature [24]. Therefore, different moisture levels can also affect starch gelatinization. BR at $54 \%$ moisture had limited available water, leaving some rice kernels, located in the lower part of the pouch, underhydrated and not able to gelatinize under the processing conditions. This resulted in uncooked rice kernels with a more vitreous aspect. Therefore, we can conclude that $54 \%$ moisture is not enough to homogeneously cook BR in pouches. On the contrary, in the pouches with 57\% and $60 \%$, the amount of moisture was enough to cook the rice evenly within the pouch ensuring homogeneous water distribution and rice grain textural attributes. These data showed that the cooking dynamic of BR in a pot and within a pouch is different and that particular care must be taken in defining the optimal moisture content of a product to ensure proper cooking of the entire pouch content and its sterilization.

\section{Texture analysis}

Hardness and stickiness of BR after re-heating in a microwave oven are shown in Table 2. Hardness and stickiness were measured as they are the most important textural attributes that affect consumer acceptability in rice [25]. As expected, water content was found to be the most important factor affecting BR hardness, with rice kernels becoming softer with increasing moisture content, as shown in Table 2. Average values of hardness resulted comparable to BR with a similar amount of moisture cooked in a pot, as shown in Fig. 2. The storage time had a significant effect on BR hardness up to 1-year shelf life. Indeed, BR hardness decreased with increasing storage time until 120 days in all samples, and then increased at longer storage times. This trend in hardness suggests the occurrence of different events at short and long storage times and is likely related to starch structural conformation and its interaction with water. It is well known that gelatinized starch is subjected to amylopectin retrogradation and staling during storage, resulting in increase of hardness

Table 2 Hardness, stickiness, and cohesiveness of brown rice cooked in pouches at different moisture content, as function of storage time

\begin{tabular}{|c|c|c|c|c|c|c|c|c|}
\hline Moisture \% & Parameter & 0 day & 40 days & 80 days & 120 days & 160 days & 270 days & 365 days \\
\hline \multirow[t]{2}{*}{54} & Hardness (N) & $150.14^{\mathrm{a}, \mathrm{b}}$ & $114.69^{\mathrm{b}, \mathrm{c}}$ & $116.70^{\mathrm{b}, \mathrm{c}}$ & $101.69^{c}$ & $157.66^{\mathrm{c}, \mathrm{b}}$ & $139.97^{\mathrm{a}, \mathrm{b}, \mathrm{c}}$ & $167.71^{\mathrm{a}}$ \\
\hline & Stickiness $\left(\mathrm{N} \mathrm{cm}^{-1}\right)$ & $3.29^{\mathrm{a}, \mathrm{b}}$ & $3.61^{\mathrm{a}, \mathrm{b}}$ & $3.69^{\mathrm{a}, \mathrm{b}}$ & $1.76^{\mathrm{a}}$ & $1.82^{\mathrm{a}}$ & $4.10^{\mathrm{a}, \mathrm{b}}$ & $5.61^{\mathrm{b}}$ \\
\hline \multirow[t]{2}{*}{57} & Hardness(N) & $124.24^{\mathrm{a}, \mathrm{b}}$ & $107.95^{\mathrm{a}, \mathrm{b}}$ & $90.93^{\mathrm{b}}$ & $90.27^{\mathrm{b}}$ & $122.30^{\mathrm{b}}$ & $114.93^{\mathrm{a}, \mathrm{b}}$ & $126.93^{\mathrm{a}, \mathrm{b}}$ \\
\hline & Stickiness $\left(\mathrm{N} \mathrm{cm}^{-1}\right)$ & $3.43^{\mathrm{a}}$ & $3.64^{\mathrm{a}}$ & $3.95^{\mathrm{a}}$ & $2.07^{\mathrm{a}}$ & $3.03^{\mathrm{a}}$ & $2.98^{\mathrm{a}}$ & $5.26^{\mathrm{a}}$ \\
\hline \multirow[t]{2}{*}{60} & Hardness & $114.63^{\mathrm{a}}$ & $86.02^{\mathrm{b}, \mathrm{c}}$ & $97.71^{\mathrm{a}, \mathrm{b}}$ & $81.96^{\mathrm{a}, \mathrm{b}}$ & $89.52^{\mathrm{bc}}$ & $100.97^{\mathrm{a}, \mathrm{b}}$ & $102.83^{\mathrm{a}, \mathrm{b}}$ \\
\hline & Stickiness $\left(\mathrm{N} \mathrm{cm}^{-1}\right)$ & $5.35^{\mathrm{a}, \mathrm{b}}$ & $5.23^{\mathrm{a}, \mathrm{b}}$ & $5.30^{\mathrm{a}, \mathrm{b}}$ & $3.52^{\mathrm{a}}$ & $4.32^{\mathrm{a}, \mathrm{b}}$ & $5.01^{\mathrm{a}, \mathrm{b}}$ & $6.17^{\mathrm{b}}$ \\
\hline
\end{tabular}

Letters indicate significant differences among samples on the same row $\mathrm{p}<0.05$ 
[26]. However, as previously observed [27] heating of BR in a microwave oven prior to analysis had a partial effect on reducing amylopectin retrogradation and conferred a fresh-like consistency to the product. It is possible that at longer storage times amylopectin undergoes modification that are not reversible with the microwave treatment used to warm rice. Amylopectin modification could have limited interaction between starch and water leading to decreased chain flexibility affecting gel-like texture. Further investigation at a molecular level will be necessary to better understand changes in the hardness of rice during shelf life.

Stickiness of BR was found to increase with increasing moisture level and storage time, as shown in Table 2. Both water $(p<0.0001)$ and time $(p<0.0001)$ had a significant effect on the stickiness of rice, however, the effect of water was predominant. Rice stickiness has been correlated with its content in amylose and protein [28]. When rice is cooked in a pot, the ratio between water to rice affects stickiness between granules, with an increase of stickiness with increasing water [29] suggesting that high leaching of starch consequent to high water content affected BR stickiness. In the native starch granules, small amylopectin molecules may entangle with large amylopectin molecules by non-covalent bonding or co-crystallize with other large amylopectin molecules, at the edges of blocklets, and are free to leach once the crystalline structure is destroyed by heating [30]. An increased degree of BR cooking can result in a higher disruption of the starch granules [31] which can lead to a larger leaching of starchy components and to a consequent increase in stickiness. Higher amount of moisture might have favored amylopectin and amylose leaching, resulting in a stickier product. $\mathrm{H}$ bonding between larger amylopectin and other amylopectin molecules is at the base of rice stickiness [30]. Thus, higher moisture levels might have favored greater interactions among amylopectin chains, generating a denser network of $\mathrm{H}$ bonds and therefore leading to higher stickiness. In this study, it was not possible to make a comparison of stickiness between BR in pouch and that in pot since a small quantity of oil was added to the pouches to reduce the adhesion among kernels during cooking.

\section{Color}

Color of $\mathrm{BR}\left(\mathrm{L}, \mathrm{a}^{*}, \mathrm{~b}^{*}\right.$ and $\Delta E$, Table 3 ) was found to be significantly affected by moisture content. Increasing moisture resulted in an increased $\mathrm{L}(p<0.0001)$, and decreasing $\mathrm{a}^{*}(p=0.0033)$, while $\mathrm{b}^{*}$ did not change significantly. These results confirm the findings of Lamberts et al. [32] but are in contrast with a previous study on BR hydration that shows decreasing levels of $\mathrm{L}$ at higher levels of hydration [33].

No significant effects of time were found on $\mathrm{L}$ and $\mathrm{a}^{*}$. On the other hand, a significant effect was observed for the values of $b^{*}$ with an increase in storage time leading to a lower level of $\mathrm{b}^{*}$. Furthermore, $\Delta E$ values indicate that the difference in color during the shelf life are perceptible after 40 days of storage by an untrained eye, showing values larger than 2 [34]. Pigment migration diffused from the bran into the endosperm can potentially explain the change in color during shelf life [32], or occurrence of oxidative process into the pouch altering the color of rice might be speculated. Further research will be necessary to determine what are the changes leading to decrease in yellowness in rice.
Table 3 Color of BR cooked in pouches at different moisture content, as function of storage time

\begin{tabular}{lllllllll}
\hline Moisture \% & Parameter & 0 day & 40 days & 80 days & 120 days & 160 days & 270 days & 365 days \\
\hline 54 & $\mathrm{~L}$ & $71.74^{\mathrm{a}, \mathrm{b}, \mathrm{c}}$ & $68.73^{\mathrm{d}, \mathrm{e}, \mathrm{f}}$ & $71.93^{\mathrm{a}, \mathrm{b}}$ & $70.25^{\mathrm{b}, \mathrm{c}, \mathrm{d}, \mathrm{e}}$ & $70.38^{\mathrm{b}, \mathrm{c}, \mathrm{d}, \mathrm{e}}$ & $73.71^{\mathrm{a}}$ & $70.96^{\mathrm{b}, \mathrm{c}, \mathrm{d}}$ \\
& $\mathrm{a}^{*}$ & $2.43^{\mathrm{a}, \mathrm{b}}$ & $2.11^{\mathrm{b}}$ & $2.16^{\mathrm{b}, \mathrm{c}}$ & $2.72^{\mathrm{a}}$ & $1.95^{\mathrm{b}, \mathrm{c}}$ & $2.43^{\mathrm{a}, \mathrm{b}}$ & $2.14^{\mathrm{b}, \mathrm{c}}$ \\
& $\mathrm{b}^{*}$ & $20.08^{\mathrm{a}}$ & $17.04^{\mathrm{c}}$ & $18.02^{\mathrm{b}, \mathrm{c}}$ & $18.13^{\mathrm{b}, \mathrm{c}}$ & $17.59^{\mathrm{c}}$ & $18.47^{\mathrm{a}, \mathrm{b}, \mathrm{c}}$ & $17.85^{\mathrm{c}}$ \\
& $\Delta E$ & 0 & 4.29 & 2.08 & 2.46 & 2.87 & 2.54 & 2.38 \\
& $\mathrm{~L}$ & $73.56^{\mathrm{a}, \mathrm{b}}$ & $72.98^{\mathrm{b}, \mathrm{c}}$ & $72.50^{\mathrm{b}, \mathrm{c}, \mathrm{d}}$ & $71.54^{\mathrm{b}, \mathrm{c}, \mathrm{d}}$ & $71.85^{\mathrm{b}, \mathrm{c}, \mathrm{d}}$ & $75.21^{\mathrm{a}}$ & $72.79^{\mathrm{b}, \mathrm{c}, \mathrm{d}}$ \\
& $\mathrm{L}$ & $2.11^{\mathrm{a}, \mathrm{b}}$ & $1.47^{\mathrm{d}, \mathrm{e}}$ & $1.76^{\mathrm{bcde}}$ & $2.02^{\mathrm{a}, \mathrm{b}, \mathrm{c}}$ & $1.67^{\mathrm{b}, \mathrm{c}, \mathrm{d}, \mathrm{e}}$ & $2.06^{\mathrm{a}, \mathrm{b}, \mathrm{c}}$ & $1.90^{\mathrm{a}, \mathrm{b}, \mathrm{c}, \mathrm{d}}$ \\
& $\mathrm{a}^{*}$ & $19.32^{\mathrm{a}}$ & $17.29^{\mathrm{a}, \mathrm{b}, \mathrm{c}}$ & $18.57^{\mathrm{ab}}$ & $17.68^{\mathrm{a}, \mathrm{b}, \mathrm{c}}$ & $17.65^{\mathrm{a}, \mathrm{b}, \mathrm{c}}$ & $17.23^{\mathrm{a}, \mathrm{b}, \mathrm{c}}$ & $16.84^{\mathrm{b}, \mathrm{c}}$ \\
& $\mathrm{b}^{*}$ & 0 & 2.21 & 1.34 & 2.60 & 2.43 & 2.45 & 2.61 \\
& $\Delta E$ & $75.95^{\mathrm{a}}$ & $73.41^{\mathrm{b}, \mathrm{c}, \mathrm{d}}$ & $73.94^{\mathrm{a}, \mathrm{b}, \mathrm{c}, \mathrm{d}}$ & $72.99^{\mathrm{b}, \mathrm{c}, \mathrm{d}}$ & $73.42^{\mathrm{b}, \mathrm{c}, \mathrm{d}}$ & $74.73^{\mathrm{a}, \mathrm{b}}$ & $72.59^{\mathrm{b}, \mathrm{c}, \mathrm{d}}$ \\
& $\mathrm{L}$ & $2.04^{\mathrm{a}, \mathrm{b}}$ & $1.53^{\mathrm{b}}$ & $1.70^{\mathrm{a}, \mathrm{b}}$ & $2.00^{\mathrm{a}, \mathrm{b}}$ & $1.62^{\mathrm{b}}$ & $2.19^{\mathrm{a}}$ & $1.90^{\mathrm{a}, \mathrm{b}}$ \\
& $\mathrm{L}^{*}$ & $19.83^{\mathrm{a}}$ & $17.18^{\mathrm{b}}$ & $18.10^{\mathrm{a}, \mathrm{b}}$ & $17.00^{\mathrm{b}}$ & $17.52^{\mathrm{b}}$ & $18.20^{\mathrm{a}, \mathrm{b}}$ & $17.74^{\mathrm{a}, \mathrm{b}}$ \\
& $\mathrm{a}^{*}$ & 0 & 3.70 & 2.67 & 4.09 & 3.45 & 2.04 & 3.96 \\
\hline
\end{tabular}

Letters indicate significant differences among samples on the same row $\mathrm{p}<0.05$ 


\section{Conclusion}

Brown rice could be a valuable ingredient in RTE meals, but the right hydration level needs to be optimized. This information was acquired using a step-by-step decision approach. Firstly, BR physiochemical properties at different hydration levels has been assessed at lab scale. From lab-scale experiments, three different hydration levels were selected and applyed for BR cooking in pouches in a pilot plant facility. It was found that, when a low moisture content (54\%) identified at lab scale, was applied in the pouch, rice was not homogeneously cooked demonstrating different cooking dynamic in different environments. Conversely, higher moisture contents resulted in uniform cooking of rice kernels without affecting its microbial safety. Significant changes in texture and color were observed in brown rice during 1-year storage time, mainly related to moisture and storage time. Samples became less hard up to 120-day storage, conversely, prolonging shelf-life led to increases in hardness that might affect the product acceptability. However, further investigation will be required to better understand the cause of the physiochemical changes during shelf life of RTE pouches. A greater understanding of the textural changes in brown rice during shelf life will potentially allow to formulate new strategies to mitigate them and to successfully employ this disregarded, but nutritionally valuable ingredient, in producing RTE meals.

Acknowledgements The authors would like to thank Mr. Gianni De Cecchi for producing the aseptic rice pouches.

Author contributions Authors NP, EV, VB contributed to the study conception and design. Material preparation, data collection and analysis were performed by EF, VG. The first draft of the manuscript was written by EF and all authors commented on previous versions of the manuscript. All authors read and approved the final manuscript.

Funding Research was partially funded by Grandi Riso S.p.A.

\section{Declarations}

Conflict of interest The authors have no relevant financial or non-financial interests to disclose.

Compliance with ethics requirements This article does not contain any studies with human or animal subjects performed by the any of the authors.

\section{References}

1. Gehlhar M, Regmi A (2005) Factors shaping global food markets. New directions in global food markets, 1:5-17

2. Shahbaz M, Bilal M, Moiz A, Zubair S, Iqbal H (2020) Food safety and COVID-19: precautionary measures to limit the spread of coronavirus at food service and retail sector. J Pure Appl Microbiol 14(suppl 1):749-756

3. Nguyen TH, Vu DC (2020) Food delivery service during social distancing: proactively preventing or potentially spreading coronavirus disease-2019? Disaster Med Public Health Prep 14(3):e9-e10

4. Boluda-Aguilar M, Taboada-Rodríguez A, López-Gómez A, Marín-Iniesta F, Barbosa-Cánovas GV (2013) Quick cooking rice by high hydrostatic pressure processing. LWT-Food Sci Technol 51(1):196-204

5. Considerations for Community-Based Organizations. Center for disease control and prevention. https://www.cdc.gov/coronavirus/ 2019-ncov/community/organizations/community-based.html\#: : text=There $\% 20$ is $\% 20$ no $\% 20$ evidence $\% 20$ that,family $\% 2$ Dstyle $\%$ 20meal. Feb 2021

6. Mohan V, Ruchi V, Gayathri R, Bai MR, Shobana S, Anjana R, Unnikrishnan R, Sudha V (2017) Hurdles in brown rice consumption. In: Manickavasagan A, Santhakumar C, Venkatachalapathy $\mathrm{N}$ (eds) brown rice. Springer, pp 255-269

7. Gujral HS, Kumar V (2003) Effect of accelerated aging on the physicochemical and textural properties of brown and milled rice. J Food Eng 59(2-3):117-121

8. Xia Q, Green BD, Zhu Z, Li Y, Gharibzahedi SMT, Roohinejad S, Barba FJ (2019) Innovative processing techniques for altering the physicochemical properties of wholegrain brown rice (Oryza sativa L.)-opportunities for enhancing food quality and health attributes. Crit Rev Food Sci Nutr 59(20):3349-3370

9. Mir SA, Bosco SJD, Shah MA (2019) Technological and nutritional properties of gluten-free snacks based on brown rice and chestnut flour. J Saudi Soc Agric Sci 18(1):89-94

10. Shobana S, Malleshi N, Sudha V, Spiegelman D, Hong B, Hu F, Willett W, Krishnaswamy K, Mohan V (2011) Nutritional and sensory profile of two Indian rice varieties with different degrees of polishing. Int J Food Sci Nutr 62(8):800-810

11. Babu PD, Subhasree R, Bhakyaraj R, Vidhyalakshmi R (2009) Brown rice-beyond the color reviving a lost health food-a review. American-Eurasian J Agron 2(2):67-72

12. Mir SA, Shah MA, Bosco SJD, Sunooj KV, Farooq S (2020) A review on nutritional properties, shelf life, health aspects, and consumption of brown rice in comparison with white rice. Cereal Chem 97(5):5-13

13. Monteiro CA, Levy RB, Claro RM, de Castro IRR, Cannon G (2010) Increasing consumption of ultra-processed foods and likely impact on human health: evidence from Brazil. Public Health Nutr 14(1):5-13

14. Kim S-M, Chung H-J, Lim S-T (2014) Effect of various heat treatments on rancidity and some bioactive compounds of rice bran. $\mathbf{J}$ Cereal Sci 60(1):243-248

15. Liu L, Guo J, Zhang R, Wei Z, Deng Y, Guo J, Zhang M (2015) Effect of degree of milling on phenolic profiles and cellular antioxidant activity of whole brown rice. Food Chem 185:318-325

16. Galanakis CM (2020) The food systems in the era of the coronavirus (COVID-19) pandemic crisis. Foods 9(4):523

17. Billiris M, Siebenmorgen T, Meullenet J-F, Mauromoustakos A (2012) Rice degree of milling effects on hydration, texture, sensory and energy characteristics. Part 1 . Cooking using excess water. J Food Eng 113(4):559-568

18. Peleg M (1976) Texture profile analysis parameters obtained by an Instron universal testing machine. J Food Sci 41(3):721-722

19. Abràmoff MD, Magalhães PJ, Ram SJ (2004) Image processing with Image. J Biophotonics Int 11(7):36-42

20. Vidal V, Pons B, Brunnschweiler J, Handschin S, Rouau X, Mestres C (2007) Cooking behavior of rice in relation to kernel physicochemical and structural properties. J Agric Food Chem 55(2):336-346 
21. Yang L, Sun Y-H, Liu Y, Mao Q, You L-X, Hou J-M, Ashraf MA (2016) Effects of leached amylose and amylopectin in rice cooking liquidon texture and structure of cooked rice. Braz Arch Biol Technol. https://doi.org/10.1590/1678-4324-2016160504

22. Littardi P, Diantom A, Carini E, Curti E, Boukid F, Vodovotz Y, Vittadini E (2019) A multi-scale characterisation of the durum wheat pasta cooking process. Int J Food Sci Technol 54(5):1713-1719

23. Schirmer M, Jekle M, Becker T (2015) Starch gelatinization and its complexity for analysis. Starch-Stärke 67(1-2):30-41

24. Eliasson AC (1980) Effect of water content on the gelatinization of wheat starch. Starch-Stärke 32(8):270-272

25. Li H, Gilbert RG (2018) Starch molecular structure: the basis for an improved understanding of cooked rice texture. Carbohydr Polym 195:9-17. https://doi.org/10.1016/j.carbpol.2018.04.065

26. Li H, Gilbert RG (2018) Starch molecular structure: The basis for an improved understanding of cooked rice texture. Carbohydr Polym. https://doi.org/10.1016/j.carbpol.2018.04.065

27. Mandala I (2005) Physical properties of fresh and frozen stored, microwave-reheated breads, containing hydrocolloids. J Food Eng 66(3):291-300

28. Hamaker B, Griffin V, Moldenhauer K (1991) Potential influence of a starch granule-associated protein on cooked rice stickiness. J Food Sci 56(5):1327-1329
29. Bett-Garber KL, Champagne ET, Ingram DA, McClung AM (2007) Influence of water-to-rice ratio on cooked rice flavor and texture. Cereal Chem 84(6):614-619. https://doi.org/10.1094/ Cchem-84-6-0614

30. Li H, Fitzgerald MA, Prakash S, Nicholson TM, Gilbert RG (2017) The molecular structural features controlling stickiness in cooked rice, a major palatability determinant. Sci Rep 7:43713. https://doi.org/10.1038/srep43713

31. Shamekh S, Forssell P, Suortti T, Autio K, Poutanen K (1999) Fragmentation of oat and barley starch granules during heating. J Cereal Sci 30(2):173-182

32. Lamberts L, De Bie E, Derycke V, Veraverbeke W, De Man W, Delcour J (2006) Effect of processing conditions on color change of brown and milled parboiled rice. Cereal Chem 83(1):80-85

33. Oli P, Ward R, Adhikari B, Torley P (2016) Colour change in rice during hydration: effect of hull and bran layers. J Food Eng 173:49-58

34. Mokrzycki W, Tatol M (2011) Colour difference $\Delta$ E-A survey. Mach Graph Vis 20(4):383-411

Publisher's Note Springer Nature remains neutral with regard to jurisdictional claims in published maps and institutional affiliations. 